\title{
Declining malaria parasite prevalence and trends of asymptomatic parasitaemia in a seasonal transmission setting in north-western Burkina Faso between 2000 and 2009-2012
}

Carolin Geiger ${ }^{1}$, Hani Kartini Agustar ${ }^{1}$, Guillaume Compaoré2 ${ }^{2}$ Boubacar Coulibaly², Ali Sié2 ${ }^{2}$ Heiko Becher ${ }^{3}$, Michael Lanzer ${ }^{1}$ and Thomas Jänisch ${ }^{1 *}$

\begin{abstract}
Background: Malaria transmission was reported to have declined in some East African countries. However, a comparable trend has not been confirmed for West Africa. This study aims to assess the dynamics of parasite prevalence and malaria species distribution over time in an area of highly seasonal transmission in Burkina Faso. The aim was also to compare frequency of asymptomatic parasitaemia between wet and dry season by parasite density status and age group.

Methods: During the years 2009-2012, six cross-sectional studies were performed in the rural village Bourasso in the Nouna Health District in north-west Burkina Faso. In subsequent rainy and dry seasons blood samples were collected to assess the parasite prevalence, species, density and clinical parameters. In total, 1,767 children and adults were examined and compared to a baseline collected in 2000.

Results: The microscopical parasite prevalence (mainly P. falciparum) measured over the rainy seasons decreased significantly from $78.9 \%$ (2000) to 58.4\%, 55.9\% and 49.3\%, respectively (2009-2011; $p<0.001$ ). The frequency of Plasmodium malariae infections (mono- and co-infections) decreased parallel to the overall parasite prevalence from $13.4 \%$ in 2000 to $2.1 \%, 4.1 \%$ and $4.7 \%$ in $2009-2011$ ( $p<0.001$ ). Comparing parasite-positive subjects from the rainy season versus dry season, the risk of fever was significantly reduced in the dry season adjusting for parasite density (grouped) and age group.

Conclusions: The results of this study suggest a decline of malaria transmission over the rainy seasons between 2000 and 2009-2011 in the region of Nouna, Burkina Faso. The decreased transmission intensity was associated with lower prevalence of $P$. malariae infections (both mono-infections and co-infections). Asymptomatic parasitaemia was more frequent in the dry season even adjusting for parasite density and age group in a multivariate regression. Possible reasons for this observation include the existence of less pathogenic Plasmodium falciparum genotypes prevailing in the dry season, or the effect of a reduced incidence density during the dry season.
\end{abstract}

Keywords: Malaria, Transmission, Parasite prevalence, Parasite density, Plasmodium falciparum, Mixed infections, Asymptomatic parasitaemia, Seasonal transmission, Clinical malaria, Burkina Faso

\footnotetext{
* Correspondence: thomas.jaenisch@urz.uni-heidelberg.de

${ }^{1}$ Department for Infectious Diseases, Parasitology, University Hospital

Heidelberg, Im Neuenheimer Feld 324, 69120, Heidelberg, Germany

Full list of author information is available at the end of the article
} 


\section{Background}

Malaria is one of the major health problems in subSaharan Africa (SSA) with approximately 174 million cases and 655,000 deaths per year, which is $>80 \%$ of cases and $>90 \%$ of malaria deaths worldwide [1]. Since the 1970 s the University of Heidelberg maintains a partnership with the Centre de Recherche en Santé Nouna (CRSN) in Nouna, Burkina Faso [2]. A number of research projects have been conducted during this cooperation with an emphasis on disease control of malaria [3-6]. A health and demographic surveillance system (HDSS) was established in 1992 and has monitored a population of 78,000 at regular intervals [2].

Malaria transmission and morbidity has been reported to have declined in areas of East Africa, which is assumed to be at least partly a result of the up-scaling of interventions (e g, availability of artemisinin combination therapy (ACT) and distribution of insecticide-treated bed nets (ITNs) [7-10]. With regard to West Africa, this trend is not well documented with the exception of few hospitalbased studies [11], which have their own limitations [12]. In this study, cross-sectional data from 2009-2012 were compared to a baseline survey from 2000, which was already published elsewhere [13]. The study was initially designed to monitor genotypic drug resistance mutations, which will be reported separately.

The epidemiology of asymptomatic malaria in different transmission settings is attracting increasing attention, because asymptomatic individuals are still able to produce gametocytes and therefore provide the reservoir for transmission $[14,15]$. The majority of malariological studies are carried out in areas of high and stable transmission and less is known about settings with marked seasonal transmission [16]. The study reports age-stratified malaria prevalence, parasite densities, mixed infections and clinical parameters in a series of population-based, cross-sectional surveys between 2000 and 2012. The surveys were carried out both in rainy and dry season in north-western Burkina Faso.

Infections with multiple Plasmodium species are common in malaria-endemic areas and it has been proposed that interaction between different species may influence the epidemiology and clinical presentation of malaria [17]. However, there is not much data about the interaction of these kinds of co-infection in different transmission settings and the existing data is conflicting. This study reports about the distribution of Plasmodium species by microscopy and PCR to monitor the variation between the different seasons over time.

\section{Methods}

\section{Study area and study design}

The study was conducted to evaluate the levels of anti-malarial drug resistance on a molecular basis in
Bourasso village, Kossi District, Burkina Faso, approximately $30 \mathrm{~km}$ from the district town Nouna. The village is located within the area of the Nouna Health and Demographic Surveillance System (HDSS), which included almost 80,000 individuals under constant demographic surveillance. The HDSS population was used as the sample frame for various epidemiological and clinical studies [5,6]. The under-five mortality rate in this area has dropped from about 40 per 1,000 person-years in the mid-1990s to below 30 per 1,000 in 2007 [2]. Malaria is hyper- to holo-endemic in this area with a transmission peak at the end of the rainy season (June to October) and reduced transmission during the dry season (November to May) [3]. The dry season consists of a cold period from November to February and a very hot phase between March and May. Bourasso had 2,263 inhabitants of different ethnic groups in March 2011 who mainly live from subsistence farming and cattle keeping. A first cross-sectional survey, which was already described elsewhere $[13,18,19]$, was carried out in October 2000 and served as a baseline for this study. Starting in 2009 until 2012 the survey was repeated both in October and April at the end of the rainy and dry season respectively.

A random list of all households in the village was generated using the data from the HDSS. All household members of the first 50-100 households were invited to participate until the target of $\sim 250$ participants was reached (inclusion criterion above six months of age). Sample size was determined with the aim of $\sim 50$ parasite positive isolates available for drug resistance testing per cycle. For the dry season an overall parasite prevalence of $\sim 15 \%$ (no previous data available) was assumed, which later had to be updated. The assumed parasite prevalence for the rainy season was $80 \%$ as it was reported in previous studies [13].

Written informed consent was taken from all patients prior to enrolment. Anthropometry for children was performed by skilled health care personnel. Each patient was examined by a physician including recent history of drugs taken. A blood sample (maximum $5 \mathrm{ml}$ ) was taken by a skilled provider. Thick and thin blood smears were prepared and parasite density counted against 200 WBC [20]. One drop of blood was applied to filter paper (either GenoCard ${ }^{\mathrm{TM}}$, Hain Lifesciences, Germany or Whatman ${ }^{\mathrm{TM}} 3 \mathrm{MM}$ chromatography paper, Brentfort, UK). The filter papers were air-dried, stored in plastic bags and transported to the Parasitology Laboratory at Heidelberg University Hospital for molecular analysis. The blood smears were fixed in methanol and stained with Giemsa solution to be analysed on the spot. Treatment according to $\mathrm{MOH}$ guidelines was provided without charge. Patients whose blood smears were positive for Plasmodium parasites were treated with 
amodiaquine-artesunate. The blood sample was divided into blood for culture and serum for pharmacological analysis of anti-malarial drugs, then frozen and transported to Heidelberg for further experiments. Ethical approval was obtained by the ethical review board of Heidelberg University Hospital and the Institutional Review Board in Nouna.

The genomic DNA was extracted from the filter papers using the Chelex-100 method [21]. The different Plasmodium species were analysed by microscopy and species-specific nested-PCR [22], the positivity for Plasmodium falciparum was the basis for the calculated PCR prevalence.

Graphs were created with Sigma-Plot 11 (Systat Software, Chicago, USA). Statistical analysis was performed using STATA 11 program (Stata Corporation, Duxbury, USA). A t-test for proportions was used to assess the significance of differences between parasite prevalences and species distributions in dry and wet season of this study. A Mann-Whitney Rank Sum Test was carried out to compare the parasite densities excluding all zero counts. To evaluate the joint influence of season, age, and parasite density on symptomatic disease/fever a logistic regression analysis was performed.

\section{Results}

During the first cross-sectional study in 2000 all inhabitants of the village Bourasso were included, in total 1,561 individuals [13]. In the years 2009-2012 a random subsample based on household numbers selected through the HDSS was invited to participate. Altogether 1,767 individuals were included (Table 1): 402, 256 and 219 in the rainy season in 2009, 2010 and 2011, and 362, 267 and 261 in the dry seasons 2010, 2011 and 2012. Participants were aged between six month and 90 years, albeit the median age was 13 (IQR 6-33). There were slightly more female individuals (52.8\%) than males in the study group 2010-2012.

Table 1 Demographic characteristics, malaria parasite prevalence (by microscopy and PCR), and proportion of symptomatic malaria infections in the study population by year (2000 vs 2009-2012) and season

\begin{tabular}{|c|c|c|c|c|}
\hline Rainy seasons & October 2000 & October 2009 & October 2010 & October 2011 \\
\hline Number of participants & 1561 & 402 & 256 & 219 \\
\hline Median age (IQR) [years] & $14(6-30)$ & $11(5-28)$ & $15(9-37)$ & $13(6-33)$ \\
\hline Age range [years] & $0-90$ & $1-89$ & $1-90$ & $1-74$ \\
\hline Proportion of male participants [\%] & 50.5 & 46.5 & 53.1 & 48.4 \\
\hline Parasite prevalence microscopy [\%] (Cl95\%) & $78.9(76.8-80.9)$ & $58.4(53.4-63.2)$ & $55.90(49.5-62.0)$ & $49.3(42.5-56.1)$ \\
\hline Parasite prevalence PCR [\%] (CI 95\%) & $92.0(87.4-95.4)^{*}$ & $66.1(61.1-70.7)^{1}$ & $68.8(62.7-74.4)^{1}$ & $73.7(67-79.7)^{2}$ \\
\hline Number of symptomatic patients [\%] ${ }^{* *}$ & & 14.7 & 9.8 & 15.1 \\
\hline Dry seasons & & April 2010 & April 2011 & April 2012 \\
\hline Number of participants & & 362 & 267 & 261 \\
\hline Median age (IQR) [years] & & $14(5-34)$ & $15(7-33)$ & $13(7-37)$ \\
\hline Age range [years] & & $1-78$ & $0-77$ & $1-78$ \\
\hline Proportion of male participants [\%] & & 44.8 & 44.9 & 45.6 \\
\hline Parasite prevalence microscopy [\%] (Cl95\%) & & $30.1(25.4-35.1)$ & $29.6(24.1-35.5)$ & $32.6(26.9-38.6)$ \\
\hline Parasite prevalence PCR [\%] (C195\%) & & $39.4(33.6-45.4)^{1}$ & $39.3(33.4-45.5)^{1}$ & $34.6(28.8-40.7)^{2}$ \\
\hline Number of symptomatic patients [\%] ${ }^{* *}$ & & 4.6 & 1.3 & 3.8 \\
\hline Combined estimates & $\begin{array}{l}\text { Combined rainy seasons } \\
2009-2011\end{array}$ & $\begin{array}{l}\text { Combined data dry seasons } \\
2010-2012\end{array}$ & & \\
\hline Number of participants & 877 & 890 & & \\
\hline Median age (IQR) [years] & $13(6-31)$ & $14(6-35)$ & & \\
\hline Age range [years] & $0-90$ & $0-78$ & & \\
\hline Proportion of male participants [\%] & 48.9 & 45.0 & & \\
\hline Parasite prevalence microscopy [\%] (Cl95\%) & $55.4(51.9-58.6)$ & $30.7(27.5-33.7)$ & & \\
\hline Parasite prevalence PCR [\%] (C195\%) & $68.7(65.4-71.8)$ & $37.9(34.7-41.2)$ & & \\
\hline Number of symptomatic patients [\%]** & 13.2 & 3.2 & & \\
\hline
\end{tabular}

*Species analysis performed for subset of 201 patients.

${ }^{* *}$ defined as microscopy positive and body temperature $>37.5^{\circ} \mathrm{C}$.

${ }^{1}$ by species-specific PCR.

${ }^{2}$ by drug resistance genotyping PCR. 
Parasite prevalence and density over time and comparing dry season and wet season

Parasite prevalence was evaluated by microscopic examination of thin and thick blood smear at four time points at the end of the rainy season (October 2000, 2009, 2010 and 2011) and three time points at the end of the dry season (April 2010, 2011 and 2012). In the survey in October 2000, $78.9 \%$ of the individuals were parasite-positive by microscopy and $92.0 \%$ by PCR. The results obtained for the years from 2009 to 2012 indicate that the overall parasite prevalence has significantly decreased (Table 1 and Figure 1). In October 2009-2012 only 58.4\%, 55.9\%, and $49.3 \%$ respectively were positive by microscopy, which was supported by the estimates by PCR (92\% in 2000 and $66.1 \%, 68.8 \%$ and $73.7 \%$ for 2009,2010 , and 2011 ( $\mathrm{p}<0.001$ ), see Table 1 ).

This effect was most pronounced for the highest age group ( $>45$ years), where the prevalence for $P$. falciparum infections dropped from $85.1 \%$ in 2000 to an average of $23.2 \%$ by microscopy in $2009-2011$ (see Figure 1). The effect was less pronounced in the age group five to 14 years, where parasite prevalence remained at around 69-80\%.

In the dry season, between April 2010 and April 2012 (no baseline value from 2000 available) the parasite prevalence did not show marked variation with values between $29.6 \%$ and $32.6 \%$ by microscopy and $34.6 \%$ and $39.3 \%$ by PCR.

As expected the parasite prevalence for Plasmodium infections differed markedly between the hot dry season and the rainy season. The pooled estimate for the rainy seasons 2009-2011 was calculated at 55.4\% (95\% CI: 51.9-58.6\%), as opposed to the pooled estimate from the dry seasons 2010-2012 with 30.6\% (95\% CI: 27.5-33.7\%;
Table 1). This variability between rain and dry season was even more pronounced with regard to parasite densities. In children below five years the geometric mean of parasite density was 2,124 parasites/ $\mu$ l (95\% CI: 1,411$3,196)$ at the end of the rainy season (pooled data from 2009-2011) - compared to 360 parasites/ $\mu \mathrm{l}$ (95\% CI: 243-535) in the dry season. The same effect was also visible in the older age groups, although not as pronounced as in children below five years of age. The pooled estimates of geometric mean parasite density of rainy season versus the dry season exhibit a statistically significant difference for all age groups (Mann-Whitney U test, p-value <0.001).

\section{Plasmodium species distribution}

Species-specific PCR, as well as microcopy, showed that $P$. falciparum is the most prevalent Plasmodium species (>95\% of infections) in this region. Besides P. falciparum, Plasmodium malariae (2.7\% of total infections) and $P$. ovale $(0.3 \%)$ were detected in microscopy. Both these species were detected as single infections or coinfections with P. falciparum (Figure 2).

The distribution of malaria species differed between the rain and dry season. Infections or co-infections with $P$. malariae were less common in the dry season with $2.7 \%$ of microscopic detectable co-infections in 2010, none in 2011 and 1.2\% single infections in 2012. The isolates from the rainy season contained $5.1 \%$ of $P$. falciparum- $P$. malariae co-infections in 2000, 1.7\% in 2009, 1.4\% in 2010 and 1.9\% in 2011. Not only co-infections were more abundant, but also singular $P$. malariae could be found in the rainy season of 2000 and 2009-2011 (with $8.27 \%, 0.4 \%, 2.7 \%$ and $2.8 \%$ respectively). In total $85.7 \%$ of the $P$. malariae or
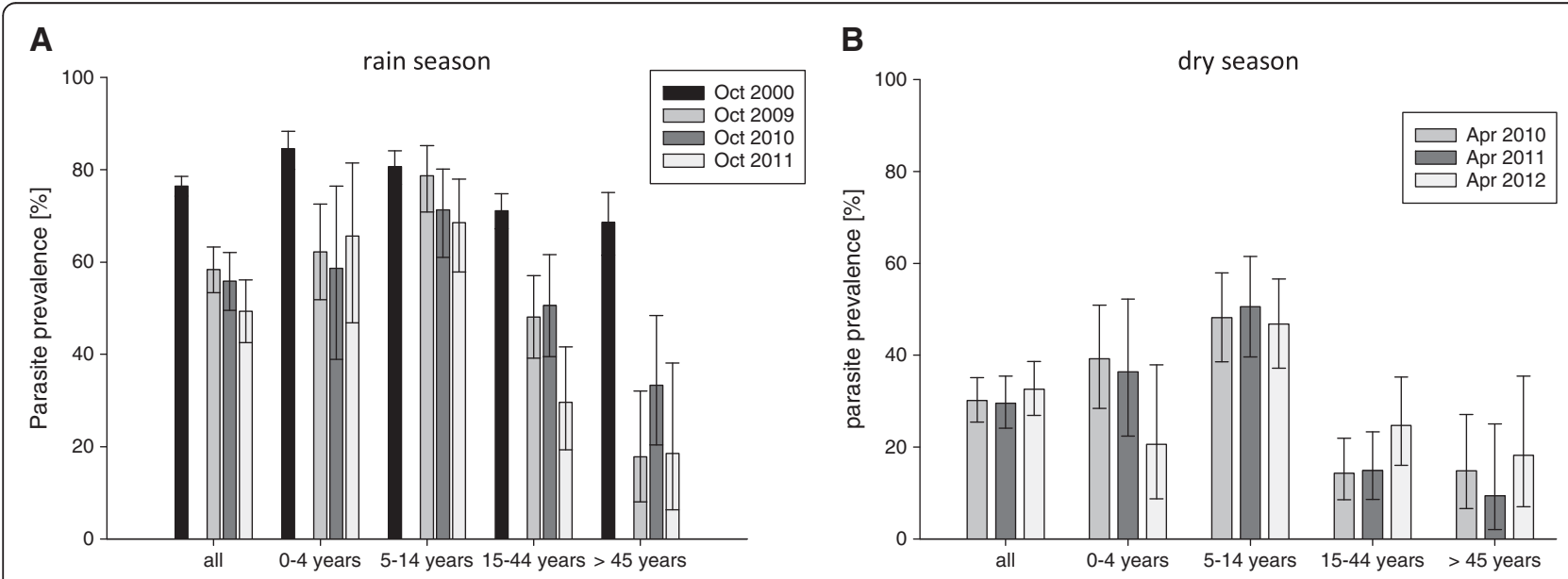

Figure 1 Parasite prevalence stratified by age group based on microscopy. Error bars represent 95\% confidence intervals. A) Rainy season baseline parasite prevalence from the rainy season of the year 2000 compared to parasite prevalence of 2009-2011; B) Dry season - parasite prevalence from 2010-2012. 


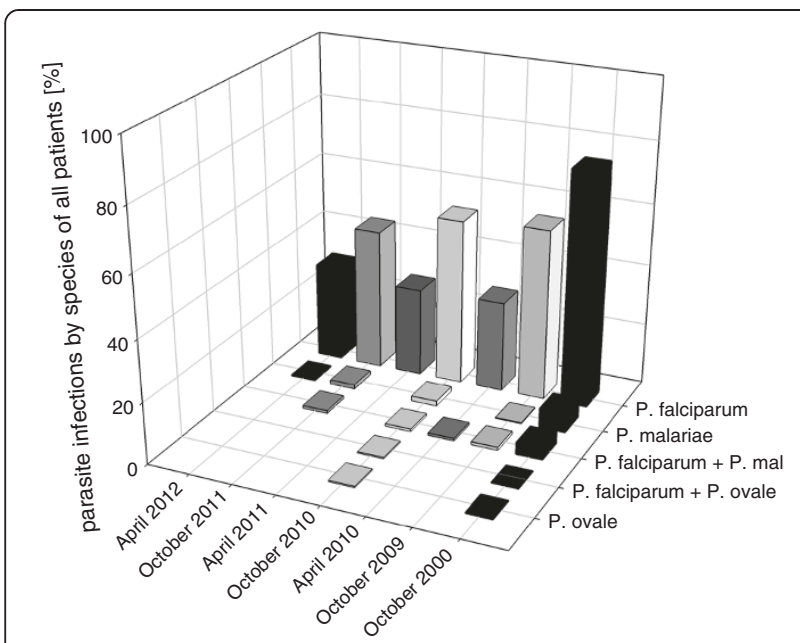

Figure 2 Plasmodium species distribution by year and season. Time is on the $x$-axis, where April represents a sampling at the end of the dry season and October a sampling at the end of the rain season of the respective year. The $y$-axis shows the proportion of positive samples by microscopy. On the z-axis the different

Plasmodium species are listed including co-infections.

P. ovale infections were found in children less than 15 years. Most of the non-falciparum infections had low parasites densities, so that only $23.8 \%$ of the isolates had counts of more than 1,000 parasites/ $\mu \mathrm{l}$.

Between 2000 to 2009-2012, this study shows a decreasing trend for P. malariae infections from $13.4 \%$ in 2000 to $2.1 \%, 4.1 \%$ and $4.7 \%$ in $2009-2011$. Comparing the estimate from 2000 with the pooled estimate from 2009-2011 the t-test for proportions is statistically significant $(\mathrm{p}<0.001)$. Plasmodium ovale was only present in a small number of blood smears of October 2000 (0.7\%) and 2010 (1.4\%) (Figure 2).

\section{Asymptomatic malaria and frequency of fever}

Asymptomatic malaria was defined as axillary body temperature $<37.5^{\circ} \mathrm{C}$ at presentation (and no history of fever) with microscopically confirmed Plasmodium infection. In the rainy season, $85-90 \%$ of the parasitepositive patients were asymptomatic $(85.3 \%$ in October 2009, $90.2 \%$ in October 2010 and $84.9 \%$ in October 2011), whereas in the dry season the number of asymptomatic individuals was higher at an average of about 97\% (95.4\% in April 2010, 98.7\% in April 2011 and 96.2\% in April 2012, see Table 1).

Symptomatic infections with high parasite density $(>1,000$ parasites/ $\mu \mathrm{l})$ were more likely to be observed in the rainy season, where $51.3 \%(59 / 115)$ of the symptomatic infections exceeded 1,000 parasites/ $\mu$ l (Table 2). During the dry season, only three of 16 symptomatic patients harboured more than 1,000 parasites/ $\mu \mathrm{l}(18.7 \%)$ and all of them occurred in children between five and 14 years.
The regression analysis revealed a significantly increased risk of fever in univariate logistic regression for patients in the rainy season as opposed to the dry season ( $p<0.001$; see Table 3). Risk of fever in the univariate regressions was also associated with parasite prevalence, age and parasite density. Children between five and 14 years experienced a slightly increased risk of fever (not statistically significant) in the univariate regression compared to the reference (children 6 months to 4 years). However, in the age group between 15 and 45 years as well as the age group $>45$ years there was a significantly decreased risk of fever compared to the reference (by 73 and $86 \%$ respectively). Presence of cough as a proxy for upper respiratory infections was not significantly associated with presence of fever.

In the multivariate regression the rainy season was still significantly associated with an increased risk of fever, adjusting for parasite density (categorical), age group, and cough. Other than dry season, high age and low parasite density are the best predictors for a reduced risk of fever, thus for being an asymptomatic parasite carrier. The OR for parasite density decreased in the multivariate regression compared to the univariate regression probably due to adjusting for age as a correlate of acquired semi-immunity to malaria.

\section{Discussion}

The data of this study showed a significant decline in parasite prevalence between the rainy season of 2000 and 2009-2011. A marked reduction of malaria incidence was described for countries in East Africa like Tanzania or Kenya [7-9,23]. However for Burkina Faso the WHO still reports rising case numbers, which could potentially be explained by increasing health service attendance and diagnosis of the disease [1]. Currently, one additional study from Nouna Health District in Burkina Faso confirms the observations of this study regarding a reduction of parasite prevalence from $85.8 \%$ to $65.5 \%$ during the rainy season and from $63.1 \%$ to $37.8 \%$ in the dry season from 1999 to 2009 in children less than four years of age. This study attributed the reduced parasite prevalence in children to the increased coverage of the population with insecticide-treated bed nets [24]. For the study that is reported here, there is no data that would allow estimating a possible mass effect of insecticide treated nets on the transmission intensity.

The reduced parasite prevalence over time was most pronounced in the group of children under five years of age - which might indeed be linked to the increased bed-net coverage. In children between five and 14 years of age the findings with regard to reduced parasite prevalence over time are not as pronounced, whereas the difference is significant again in older age. One hypothesis could be that this effect is associated with the age-specific role of immune mechanisms developing in 
Table 2 Asymptomatic parasite carriers by parasite density (microscopy) and age group comparing rain and dry season

\begin{tabular}{|c|c|c|c|c|c|c|}
\hline & $\begin{array}{l}\% \text { asymptomatic carriers/ } \\
\text { total carriers }\end{array}$ & $\begin{array}{l}1-1,000 \\
\text { parasites/ } \mu \mathrm{l}\end{array}$ & 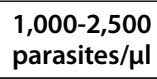 & $\begin{array}{l}2,500-5,000 \\
\text { parasites/ } \mu \mathrm{l}\end{array}$ & $\begin{array}{l}5,000-10,000 \\
\text { parasites/ } / \mu \mathrm{l}\end{array}$ & $\begin{array}{l}>10,000 \\
\text { parasites/ } \mu \mathrm{l}\end{array}$ \\
\hline \multicolumn{7}{|l|}{ Rainy season } \\
\hline $0-4$ years & $68.1(64 / 94)$ & $80.6(25 / 31)$ & $61.5(8 / 13)$ & $75.0(9 / 12)$ & $76.5(13 / 17)$ & $42.9(9 / 21)$ \\
\hline \multicolumn{7}{|l|}{ (\% asymptomatic carriers/total carriers) } \\
\hline $5-14$ years & $72.6(170 / 234)$ & $75.9(101 / 133)$ & $80.5(33 / 41)$ & $69.0(20 / 29)$ & $55.6(10 / 18)$ & $46.2(6 / 13)$ \\
\hline \multicolumn{7}{|l|}{ (\% asymptomatic carriers/total carriers) } \\
\hline $15-44$ years & $86.4(108 / 125)$ & $86.8(92 / 106)$ & $81.8(9 / 11)$ & $100(4 / 4)$ & $(3 / 3)$ & $(0 / 1)$ \\
\hline \multicolumn{7}{|l|}{ (\% asymptomatic carriers/total carriers) } \\
\hline$>45$ years & $86.2(25 / 29)$ & $84.6(22 / 26)$ & $(2 / 2)$ & $(0 / 0)$ & $(0 / 0)$ & $(1 / 1)$ \\
\hline \multicolumn{7}{|l|}{ (\% asymptomatic carriers/total carriers) } \\
\hline All & $76.1(367 / 482)$ & $81.1(240 / 296)$ & $77.6(52 / 67)$ & $73.3(33 / 45)$ & $68.4(26 / 38)$ & $44.4(16 / 36)$ \\
\hline \multicolumn{7}{|l|}{ (\% asymptomatic carriers/total carriers) } \\
\hline \multicolumn{7}{|l|}{ Dry season } \\
\hline $0-4$ years & $92.5(49 / 53)$ & $90.9(40 / 44)$ & $(2 / 2)$ & $100(4 / 4)$ & $(2 / 2)$ & $(1 / 1)$ \\
\hline \multicolumn{7}{|l|}{ (\% asymptomatic carriers/total carriers) } \\
\hline $5-14$ years & $93.2(136 / 146)$ & $94.0(109 / 116)$ & $100(17 / 17)$ & $83.3(5 / 6)$ & $100(4 / 4)$ & $(1 / 3)$ \\
\hline \multicolumn{7}{|l|}{ (\% asymptomatic carriers/total carriers) } \\
\hline $15-44$ years & $96.3(52 / 54)$ & $96.0(48 / 50)$ & $(3 / 3)$ & $(1 / 1)$ & $(0 / 0)$ & $(0 / 0)$ \\
\hline \multicolumn{7}{|l|}{ (\% asymptomatic carriers/total carriers) } \\
\hline$>45$ years & $100(16 / 16)$ & $100(15 / 15)$ & $(1 / 1)$ & $(0 / 0)$ & $(0 / 0)$ & $(0 / 0)$ \\
\hline \multicolumn{7}{|l|}{ (\% asymptomatic carriers/total carriers) } \\
\hline All & $94.1(253 / 269)$ & $94.2(212 / 225)$ & $100(23 / 23)$ & $90.9(10 / 11)$ & $100(6 / 6)$ & $50(2 / 4)$ \\
\hline (\% asymptomatic carriers/total carriers) & & & & & & \\
\hline
\end{tabular}

populations exposed to malaria. The transmission decline if confirmed would also have an impact on acquisition of naturally acquired (semi-) immunity and consequently also ratio of symptomatic disease to asymptomatic disease $[25,26]$. Close monitoring provides important data that could help to improve malaria control also taking into account the experience of countries that have achieved similar transmission reductions.

\section{Mixed Plasmodium infections}

The frequency of mixed infections with $P$. malariae decreased significantly during the study period from 2000 to 2009-2011. It was shown before in Malawi, that higher $P$. falciparum prevalence was linked with higher prevalence of minority species, which could be explained by the raised possibility of species co-transmission [27]. Furthermore, another study in Burkina Faso showed that the use of ITNs reduced the prevalence for $P$. malariae infections more substantially than that of P. falciparum [28]. As ITNs are now highly abundant in the study area, this could be another explanation for the different prevalence of $P$. malariae infections and co-infections between the baseline from the year 2000 and the results from 2009-2012.
The observation, that higher transmission is associated with greater species diversity, would also be in accordance to the results of this study for the dry season, which is a low transmission scenario. Prevalence for $P$. malariae is low in the April surveys with only three, zero or one infected patient for the years 20102012. These results are supported by similar findings of one study in Burkina Faso, near Bobo-Dioulasso, about $230 \mathrm{~km}$ south from the study site Nouna, where prevalence for $P$. malariae infections was reduced by approximately half in March and May compared to October and December [29]. However, previous findings in two other West African countries indicate that $P$. malariae exhibits opposing seasonal fluctuation with $P$. falciparum [30,31], which leads to increased prevalence of $P$. malariae during the dry season in those study areas.

Most of the infections and co-infections with P. malariae in this study showed low parasite density levels $<1,000$ parasites/ $\mu l$. It is known that the blood stages of this Plasmodium species persist in the blood at low levels for long periods; some believe even lifelong [17,32]. This could potentially lead to an underestimation of the actual $P$. malariae burden, as the microscopy detection limit 
Table 3 Univariate and multivariate logistic regression analysis on presence of fever (axillary body temperature $>37.5^{\circ} \mathrm{C}$ ) in 1,767 subjects participating in six surveys from 2009 to 2012 in Bourasso village, Nouna Health District, north-western Burkina Faso

\begin{tabular}{|c|c|c|c|c|}
\hline & \multicolumn{3}{|c|}{ Univariate } & \multirow{2}{*}{$\frac{\text { Multivariate }}{\text { OR (p-value) }}$} \\
\hline & No fever & Fever & OR (p-value) & \\
\hline \multicolumn{5}{|l|}{ Season } \\
\hline Wet season & $69.9 \%(613 / 877)$ & $30.1(264 / 877)$ & Reference & reference \\
\hline Dry season & $88.8 \%(790 / 890)$ & $11.2(100 / 890)$ & $0.29(<0.001)$ & $0.31(<0.001)$ \\
\hline \multicolumn{5}{|l|}{ Age groups* } \\
\hline $0-4$ years & $77.7 \%(240 / 309)$ & $23.3 \%(69 / 309)$ & Reference & Reference \\
\hline $5-14$ years & $73.1 \%(457 / 625)$ & $26.9 \%(168 / 625)$ & $1.28(0.13)$ & $1.39(0.06)$ \\
\hline $15-24$ years & $79.5 \%(186 / 234)$ & $20.5 \%(48 / 234)$ & $0.90(0.61)$ & $0.98(0.94)$ \\
\hline $25-45$ years & $82.9 \%(295 / 356)$ & $17.1 \%(61 / 356)$ & $0.72(0.09)$ & $0.88(0.53)$ \\
\hline$>45$ years & $92.5 \%(221 / 239)$ & $7.5 \%(18 / 239)$ & $0.28(<0.001)$ & $0.31(<0.001)$ \\
\hline \multicolumn{5}{|l|}{ Parasite prevalence } \\
\hline Slide positive [\%] (total number) & $73.7(558 / 757)$ & $26.3(199 / 757)$ & $1.83(<0.001)$ & \\
\hline \multicolumn{5}{|l|}{ Parasite density** } \\
\hline no parasites & $60.6 \%(849 / 1401)$ & $45.2 \%(164 / 363)$ & Reference & Reference \\
\hline 1-500 parasites/ $\mu \mathrm{l}$ & $22.9 \%(321 / 1401)$ & $24.8 \%(90 / 363)$ & $1.45(0.01)$ & $1.00(0.96)$ \\
\hline 501-1000 parasites/ $\mu \mathrm{l}$ & $5.9 \%(83 / 1401)$ & $7.4 \%(27 / 363)$ & $1.68(0.028)$ & $1.03(0.90)$ \\
\hline 1001-2500 parasites/ $\mu \mathrm{l}$ & $4.6 \%(64 / 1401)$ & $7.2 \%(26 / 363)$ & $2.10(0.003)$ & $1.08(0.77)$ \\
\hline 2501-5000 parasites/ $\mu \mathrm{l}$ & $2.9 \%(40 / 1401)$ & $4.4 \%(16 / 363)$ & $2.07(0.018)$ & $0.97(0.92)$ \\
\hline 5001-10 000 parasites $/ \mu \mathrm{l}$ & $1.9 \%(26 / 1401)$ & $5.0 \%(18 / 363)$ & $3.58(<0.001)$ & $1.69(0.12)$ \\
\hline > 10000 parasites $/ \mu \mathrm{l}$ & $1.3 \%(18 / 1401)$ & $6.2 \%(22 / 363)$ & $6.33(<0.001)$ & $3.08(0.001)$ \\
\hline cough & $77.3 \%(136 / 176)$ & $22.7(40 / 176)$ & $1.15(0.462)$ & $0.96(0.85)$ \\
\hline
\end{tabular}

*Information on age missing in four patients.

** Information on parasite density missing in three patients.

is low. These results demonstrate that PCR is a more sensitive tool to monitor the minor abundant Plasmodium species. Despite the use of molecular techniques, $P$. ovale infections in the study were still rare and limited to the high transmission time of the rainy season. Studies in children from Tanzania and Ivory Coast $P$. malariae were found to reduce fever and symptomatic disease [33,34]. The results obtained in this study show a trend, where in P. malariae and P. falciparum co-infections $30 \%$ of the patients were symptomatic, while in single $P$. falciparum $37.5 \%$ were symptomatic. However, the difference is not significant and the number of co-infected patients is low in the study.

\section{Asymptomatic parasitaemia}

Asymptomatic parasitaemia was more frequent in the dry season even adjusting for parasite density and age group in a multivariate regression. Possible reasons for this observation include the existence of less pathogenic $P$. falciparum genotypes prevailing in the dry season, or the effect of a reduced incidence density during the dry season. The latter hypothesis would assume that clinical disease is also a cumulative result of a high number of sequential infections.

Evidence from Sudan suggests that chronic infections during the dry season are often multiclonal [35] and are competent to produce gametocytes [36]. It has also been reported that in patients with persistent Plasmodium infections during the dry season, a disease outbreak was associated with new genotypes, although it is not clear if this was a result of genetic crossing in the re-emerging Anopheles vector or if the genotype was imported from outside [37].

\section{Limitations}

The age and sex distribution of the cross-sectional surveys is comparable over the years and also compared to the initial survey, which included the whole population of the village. The proportion of male participants was slightly reduced in some of the surveys, probably due to the fact that male inhabitants were busy with agricultural work. As prevalence and other epidemiological markers are not sexspecific this should not influence the results of this study. 


\section{Conclusions}

The results of this study suggest a decline of malaria transmission over the rainy seasons between 2000 and 2009-2011 in the region of Nouna, Burkina Faso. The parasite prevalence in the dry season was higher than expected with $~ 30 \%$ by microscopy throughout the years 2010-2012.

Asymptomatic parasitaemia was more frequent in the dry season even adjusting for parasite density and age group in a multivariate regression. Furthermore, the results of the study could show that reduced parasite prevalence for $P$. falciparum was associated with lower prevalence of $P$. malariae infections.

\section{Competing interests}

The authors declare that they have no competing interests.

\section{Authors' contributions}

CG participated in the data collection, carried out laboratory investigations, analysed the data, produced figures and tables, and prepared the original draft. HKA carried out laboratory investigations and interpreted the data. GC, $\mathrm{BC}$, and AS coordinated the data collection, contributed to the conception and design of the study, and interpreted the data. ML and $\mathrm{HB}$ analysed and interpreted the data. TJ conceived and coordinated the study, analysed the data, and prepared the original draft. All authors contributed to the drafts, read and approved the final manuscript.

\section{Acknowledgements}

The study and CG were supported by the German Research Foundation (DFG), PhD programme GRK 793 "Epidemiology of communicable and chronic, non-communicable diseases and their interrelationships" and the SFB 544 "Control of Tropical Infectious Diseases". We express our sincere gratitude to the study team of the Nouna Health Research Centre (CRSN) and to all the inhabitants of Bourasso village.

\section{Author details}

${ }^{1}$ Department for Infectious Diseases, Parasitology, University Hospital Heidelberg, Im Neuenheimer Feld 324, 69120, Heidelberg, Germany. ${ }^{2}$ Centre de Recherche en Santé à Nouna, BP02, Nouna, Burkina Faso. ${ }^{3}$ University Hospital Heidelberg, Institute for Public Health, Im Neuenheimer Feld 324 69120, Heidelberg, Germany.

Received: 7 December 2012 Accepted: 14 January 2013 Published: 22 January 2013

\section{References}

1. WHO: World Malaria Report 2011. Geneva: WHO press; 2011.

2. Sie A, Louis VR, Gbangou A, Muller O, Niamba L, Stieglbauer G, Ye M, Kouyate B, Sauerborn R, Becher $\mathrm{H}$ : The health and demographic surveillance system (HDSS) in Nouna, Burkina Faso, 1993-2007. Glob Health Action 2010, 3. doi:10.3402/gha.v3i0.5284.

3. Muller $\mathrm{O}$, Becher $\mathrm{H}$, van Zweeden AB, Ye Y, Diallo DA, Konate AT, Gbangou A, Kouyate B, Garenne M: Effect of zinc supplementation on malaria and other causes of morbidity in west African children: randomised double blind placebo controlled trial. BMJ 2001, 322:1567.

4. Muller O, Traore C, Kouyate B, Ye Y, Frey C, Coulibaly B, Becher H: Effects of insecticide-treated bednets during early infancy in an African area of intense malaria transmission: a randomized controlled trial. Bull World Health Organ 2006, 84:120-126.

5. Louis VR, Bals J, Tiendrebeogo J, Bountogo M, Ramroth H, De Allegri M, Traore C, Beiersmann C, Coulibaly B, Yé M, Jahn A, Becher H, Müller O: Long-term effects of malaria prevention with insecticide-treated mosquito nets on morbidity and mortality in African children: randomised controlled trial. Trop Med Int Health 2012, 17:733-741.

6. Kouyate B, Some F, Jahn A, Coulibaly B, Eriksen J, Sauerborn R, Gustafsson L, Tomson G, Becher $\mathrm{H}$, Mueller $\mathrm{O}$ : Process and effects of a community intervention on malaria in rural Burkina Faso: randomized controlled trial. Malar J 2008, 7:50

7. O'Meara WP, Bejon P, Mwangi TW, Okiro EA, Peshu N, Snow RW, Newton CR, Marsh K: Effect of a fall in malaria transmission on morbidity and mortality in Kilifi, Kenya. Lancet 2008, 372:1555-1562.

8. Mmbando BP, Vestergaard LS, Kitua AY, Lemnge MM, Theander TG, Lusingu JP: A progressive declining in the burden of malaria in north-eastern Tanzania. Malar J 2010, 9:216.

9. Schellenberg D, Menendez C, Aponte J, Guinovart C, Mshinda H, Tanner M, Alonso P: The changing epidemiology of malaria in Ifakara Town southern Tanzania. Trop Med Int Health 2004, 9:68-76.

10. Karema C, Aregawi MW, Rukundo A, Kabayiza A, Mulindahabi M, Fall IS, Gausi K, Williams RO, Lynch M, Cibulskis R, Fidele N, Nyemazi JP, Ngamije D, Umulisa I, Newman R, Binagwaho A: Trends in malaria cases, hospital admissions and deaths following scale-up of anti-malarial interventions, 2000-2010, Rwanda. Malar J 2012, 11:236.

11. Ceesay SJ, Casals-Pascual C, Nwakanma DC, Walther M, Gomez-Escobar N, Fulford AJ, Takem EN, Nogaro S, Bojang KA, Corrah T, Jaye MC, Taal MA, Sonko AA, Conway DJ: Continued decline of malaria in The Gambia with implications for elimination. PLOS One 2010, 5:e12242.

12. Rowe AK, Kachur SP, Yoon SS, Lynch M, Slutsker L, Steketee RW: Caution is required when using health facility-based data to evaluate the health impact of malaria control efforts in Africa. Malar J 2009, 8:209.

13. Stich A, Oster N, Abdel-Aziz IZ, Stieglbauer G, Coulibaly B, Wickert H, McLean J, Kouyate BA, Becher H, Lanzer M: Malaria in a holoendemic area of Burkina Faso: a cross-sectional study. Parasitol Res 2006, 98:596-599.

14. Doumbia SO, Ndiaye D, Koita OA, Diakite M, Nwakanma D, Coulibaly M, Traore SF, Keating J, Milner DA Jr, Ndiaye JL, Sene PD, Ahouidi A, Dieye TN, Gaye O, Okebe J, Ceesay SJ, Ngwa A, Oriero EC, Konaté L, Sy N, Jawara M, Faye O, Kéita M, Cissé M, Sogoba N, Poudiougou B, Diawara S, Sangaré L, Coulibaly T, Seck I, et al: Improving malaria control in West Africa: interruption of transmission as a paradigm shift. Acta Trop 2012, 121:175-183.

15. Laishram DD, Sutton PL, Nanda N, Sharma VL, Sobti RC, Carlton JM, Joshi H: The complexities of malaria disease manifestations with a focus on asymptomatic malaria. Malar J 2012, 11:29.

16. Cairns M, Roca-Feltrer A, Garske T, Wilson AL, Diallo D, Milligan PJ, Ghani AC, Greenwood BM: Estimating the potential public health impact of seasonal malaria chemoprevention in African children. Nat Comm 2012, 3:881.

17. Mueller I, Zimmerman PA, Reeder JC: Plasmodium malariae and Plasmodium ovale-the "bashful" malaria parasites. Trends Parasitol 2007 23:278-283.

18. Abdel-Aziz IZ, Oster N, Stich A, Xoulibaly B, Guigemdé W, Wickert H, Andrews KT, Kouyaté B, Lanzer M: Association of Plasmodium falciparum isolates encoding the $\mathrm{P}$. falciparum chloroquine resistance transporter gene K76T polymorphism with anemia and splenomegaly, but not with multiple infections. Am J Trop Med Hyg 2005, 72:252-255.

19. Oster N, Abdel-Aziz IZ, Stich A, Coulibaly B, Kouyate B, Andrews KT, McLean JE, Lanzer M: Comparison of different PCR protocols for the detection and diagnosis of Plasmodium falciparum. Parasitol Res 2005, 97:424-428

20. Trape JF: Rapid evaluation of malaria parasite density and standardization of thick smear examination for epidemiological investigations. Trans R Soc Trop Med Hyg 1985, 79:181-184.

21. Plowe CV, Djimde A, Bouare M, Doumbo O, Wellems TE: Pyrimethamine and proguanil resistance-conferring mutations in Plasmodium falciparum dihydrofolate reductase: polymerase chain reaction methods for surveillance in Africa. Am J Trop Med Hyg 1995, 52:565-568.

22. Snounou G, Viriyakosol S, Zhu XP, Jarra W, Pinheiro L, do Rosario VE, Thaithong S, Brown KN: High sensitivity of detection of human malaria parasites by the use of nested polymerase chain reaction. Mol Biochem Parasitol 1993, 61:315-320.

23. Jaenisch T, Sullivan DJ, Dutta A, Deb S, Ramsan M, Othman MK, Gaczkowski $R$, Tielsch J, Sazawal S: Malaria incidence and prevalence on Pemba island before the onset of the successful control intervention on the Zanzibar archipelago. Malar J 2010, 9:32.

24. Beiersmann C, Bountogo M, Tiendrebeogo J, De Allegri M, Louis VR, Coulibaly B, Ye M, Mueller O: Falciparum malaria in young children of rural Burkina Faso: comparison of survey data in 1999 with 2009. Malar J 2011, 10:296. 
25. Doolan DL, Dobano C, Baird JK: Acquired immunity to malaria. Clin Microbiol Rev 2009, 22:13-36.

26. D'Acremont V, Lengeler C, Genton B: Reduction in the proportion of fevers associated with Plasmodium falciparum parasitaemia in Africa: a systematic review. Malar J 2010, 9:240.

27. Bruce MC, Macheso A, Kelly-Hope LA, Nkhoma S, McConnachie A, Molyneux ME: Effect of transmission setting and mixed species infections on clinical measures of malaria in Malawi. PLoS One 2008, 3:e2775.

28. Habluetzel A, Cuzin N, Diallo DA, Nebie I, Belem S, Cousens SN, Esposito F: Insecticide-treated curtains reduce the prevalence and intensity of malaria infection in Burkina Faso. Trop Med Int Health 1999, 4:557-564.

29. Boudin C, Robert V, Verhave JP, Carnevale P, Ambroise-Thomas P: Plasmodium falciparum and P. malariae epidemiology in a West African village. Bull World Health Organ 1991, 69:199-205.

30. Molineaux L, Storey J, Cohen JE, Thomas A: A longitudinal study of human malaria in the West African Savanna in the absence of control measures: relationships between different Plasmodium species, in particular P. falciparum and P. malariae. Am J Trop Med Hyg 1980, 29:725-737.

31. Barnish G, Maude GH, Bockarie MJ, Erunkulu OA, Dumbuya MS, Greenwood BM: Malaria in a rural area of Sierra Leone. II. Parasitological and related results from pre- and post-rains clinical surveys. Ann Trop Med Parasitol 1993, 87:137-148.

32. Collins WE, Jeffery GM: Plasmodium malariae: parasite and disease. Clin Microbiol Rev 2007, 20:579-592.

33. Black J, Hommel M, Snounou G, Pinder M: Mixed infections with Plasmodium falciparum and P. malariae and fever in malaria. Lancet 1994, 343:1095.

34. Alifrangis M, Lemnge MM, Moon R, Theisen M, Bygbjerg I, Ridley RG, Jakobsen PH: IgG reactivities against recombinant Rhoptry-Associated Protein-1 (rRAP-1) are associated with mixed Plasmodium infections and protection against disease in Tanzanian children. Parasitology 1999, 119:337-342.

35. Babiker HA, Abdel-Muhsin AA, Hamad A, Mackinnon MJ, Hill WG, Walliker D: Population dynamics of Plasmodium falciparum in an unstable malaria area of eastern Sudan. Parasitology 2000, 120:105-111.

36. Abdel-Wahab A, Abdel-Muhsin AM, Ali E, Suleiman S, Ahmed S, Walliker D, Babiker HA: Dynamics of gametocytes among Plasmodium falciparum clones in natural infections in an area of highly seasonal transmission. J Infect Dis 2002, 185:1838-1842.

37. Babiker HA: Unstable malaria in Sudan: the influence of the dry season. Plasmodium falciparum population in the unstable malaria area of eastern Sudan is stable and genetically complex. Trans R Soc Trop Med Hyg 1998, 92:585-589.

doi:10.1186/1475-2875-12-27

Cite this article as: Geiger et al:: Declining malaria parasite prevalence and trends of asymptomatic parasitaemia in a seasonal transmission setting in north-western Burkina Faso between 2000 and 2009-2012. Malaria Journal 2013 12:27.

\section{Submit your next manuscript to BioMed Central and take full advantage of:}

- Convenient online submission

- Thorough peer review

- No space constraints or color figure charges

- Immediate publication on acceptance

- Inclusion in PubMed, CAS, Scopus and Google Scholar

- Research which is freely available for redistribution

Submit your manuscript at www.biomedcentral.com/submit
C Biomed Central 